MOVING THE DIAL ON YOUTH WELLBEING

A YouthREX Research to Practice Report

Bridging Programs: Pathways to Equity

in Post-Secondary

Education

by Jacqueline Stol, Rebecca Houwer and Dr. Sarah Todd

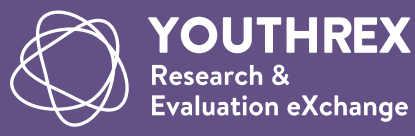




\author{
AUTHORS \\ Jacqueline Stol Research Assistant, YouthREX \\ Masters Student, School of Social Work, Carleton University \\ Rebecca Houwer Knowledge Exchange Manager, YouthREX \\ PhD Candidate, Faculty of Education, York University \\ Dr. Sarah Todd Academic Lead, YouthREX's Eastern Hub \\ Associate Professor in Social Work, Carleton University \\ CONTRIBUTORS \\ Yumi Numata \\ Knowledge Mobilization \& Communications Manager, YouthREX \\ Anita Sekharan \\ Lead Designer and Digital Content Manager, YouthREX
}

This report is licensed under a Creative

Commons Attribution - NonCommercial 2.5

\section{Canada License.}

This report may be reprinted or distributed, including on the Internet, without permission, provided it is not offered for sale, the content is not altered, and the source is properly credited.

\section{This research was commissioned by the} Youth Research and Evaluation eXchange.

YouthREX is primarily funded by the Ontario Ministry of Children and Youth Services with extensive contributions from York University and the four partner universities: Carleton University; King's College University at Western University; Laurentian University and Lakehead University.

\section{YouthREX}

School of Social Work

York University

4700 Keele Street

Toronto, Ontario M3J 1P3

Fax: 416-650-3861

youthrex@yorku.ca

www.youthrex.com

www.exchange.youthrex.com

\begin{abstract}
Participation in post-secondary education (PSE) enhances the quality of life and wellbeing of individuals, communities, and societies overall. Unfortunately, certain groups of young people are underrepresented in PSE. Bridging programs have the potential to respond to the many and often overlapping challenges underrepresented youth face by providing individualized and alternative pathways for entrance, persistence, and attainment of PSE credentials. This report reviews the social policy context for PSE access programs, describes youth who are underrepresented in PSE, presents case study examples, and outlines key concepts related to bridging programs. We then selectively review and summarize evidence related to program design, student persistence, and necessary institutional supports for successful bridging programs. The report concludes with a series of recommended strategies for leveraging bridging programs in order to increase equity in PSE.
\end{abstract}

\section{KEYWORDS}

bridging programs, post-secondary education, pathways, educational attainment

\section{APA CITATION}

Stol, J., Houwer, R., Todd, Sarah. (2016). Bridging Programs: Pathways to Equity in Post-Secondary Education. Youth Research and Evaluation eXchange (YouthREX). Toronto, ON.

\section{RESEARCH TO PRACTICE REPORTS}

Moving the Dial on Youth Wellbeing is a series of multi-source plain language Research to Practice reports that selectively review, synthesize and translate practice-relevant research, evaluation and experiential evidence applicable to the work of youth sector stakeholders across Ontario. 


\section{TABLE OF CONTENTS}

1.0 Introduction: Setting the Context 5

Scope of this Report 5

Who ls lt For? $\quad 6$

Guiding Questions 6

Methodology 6

Federal and Ontario Context 6

2.0 What Do We Know? 8

Equity In Post-Secondary Education Participation: 10

Who is Underrepresented?

Barriers To Post-Secondary Education Participation $\quad 12$

Bridging Programs: Addressing Barriers To Post-Secondary 13

Education Participation

$\begin{array}{lll}\text { 3.0 Designing Bridging Programs: Evidence-based Strategies } & 16\end{array}$

Assessing the Evidence for Bridging Programs 16

Facilitating Post-Seconday Education Persistence and Completion 18

4.0 Moving the Dial: Recommendations for Practice 21

$\begin{array}{llr}5.0 & \text { Conclusion } & 25\end{array}$

$\begin{array}{llr}6.0 & \text { References } & 26\end{array}$

$\begin{array}{lll}7.0 & \text { Appendices } & 27\end{array}$ 
Government, institutional, program,

and research-based responses

aimed at improving accessibility

to post-secondary education have

failed to adequately consider the

unique contexts and needs of

underrepresented groups. Their

responses have too often focused

on financial aid and have not taken

into account the complex range of

barriers affecting a young person's

participation in post-secondary

education. 


\section{1 // INTRODUCTION: SETTING THE CONTEXT}

Participation in post-secondary education (PSE)

enhances the quality of life and wellbeing of

individuals, communities, and societies overall. ${ }^{1}$

In today's competitive labour market, a high school diploma is not enough to open doors to gainful employment opportunities. The Higher Education Quality Council of Ontario (HEQCO) recently released a comprehensive report on the impact and performance of PSE in Canada.

They found that every province demonstrated a positive relationship between participation in PSE and individual earnings, citizen engagement, and economic contribution. Clearly, accessible PSE institutions are critical for young people and for the creation of a sustainable economy and a high quality of life in Canada. ${ }^{2}$

While PSE completion is important for young people and for our nation as a whole, unfortunately, certain population groups are underrepresented in post-secondary institutions. For these young people, their pathway options are limited or restricted by complex barriers to access and persistence in PSE. As a result, underrepresented students need PSE institutions to provide a number of alternative pathways that recognize and support their unique needs, both financial and nonfinancial. ${ }^{3}$ PSE bridging programs play an important role in reducing barriers to participation by responding to existing barriers and providing services that prepare underrepresented students for quality participation in post-secondary education. ${ }^{4}$

Bridging programs strive to create accessible pathways to PSE participation and completion for youth facing multiple and complex barriers. The challenge of accessing PSE for youth facing multiple barriers is increasingly shouldered by youth sector organizations and frontline youth workers. Cuts to funding for guidance counsellors has resulted in many youth being ill-equipped to navigate the challenging PSE admissions terrain. ${ }^{5}$ Without support from guidance counsellors, many young people turn to their communitybased youth organizations, youth employment counsellors, youth transition workers, youth outreach workers, frontline youth service workers, and peers for insight, guidance and support.

Increasingly, bridging programs are collaboratively designed in partnership with community-based organizations, as well as with employment, education, and government bodies that have a stake in ensuring that all young people have an opportunity to contribute to the future of Canada.

\section{SCOPE OF THIS REPORT}

The purpose of this report is to review the evidence related to how well existing PSE bridging programs support and enable underrepresented youth to access, persist, and complete a PSE program. To close the PSE opportunity gap and "move the dial" on PSE access and completion equity, our report is intended to serve as an evidence-based resource for youthserving organizations and individuals interested in developing and/or evaluating bridging programs. This report provides a point-in-time summary of the evidence-base related to PSE bridging programs. As this field of research evolves, so will the data. As such, this report presents a snapshot of both the academic and grey literature, highlighting promising practices that are evidence-based and that, as a result, provide an important starting point for those interested in program development and/or evaluation.
1 Educational Policy Institute, 2009; Norrie \& Zhao, 2011; Weingarten et al., 2015

${ }^{2}$ Canadian Council on Learning, 2011; Educational Policy Institute, 2009; Weingarten et al., 2015

${ }^{3}$ Malik, Guan, Vetere, Abramovitch, 2011
${ }^{4}$ CSA, OSTA \& OUSA; 2011

${ }^{5}$ Hamlin, Hagen Cameron \& Watkins, 2016 


\section{WHO IS IT FOR?}

This report is aimed at two groups: a) people working with youth in the community who are interested in establishing or collaborating with a bridging program; and b) people working in PSE who would like to invest resources in bridging programs for young people who could contribute a great deal to university and college life, but whose academic record may not meet admission requirements.

\section{GUIDING QUESTIONS}

This paper seeks to:

- Review and assess the most effective bridging strategies and/or programs for engaging underrepresented youth in PSE

- Present evaluated strategies for engaging young people in bridging opportunities and for keeping them engaged and supported after transitioning to PSE

- Reflect on the challenges in the delivery of bridging programs and examine case studies of programs that have achieved significant success

\section{METHODOLOGY}

The literature synthesized in this report, while not comprehensive, draws on an array of sources:

\section{Sources}

- Academic and peer-reviewed journals and books

- Grey literature (policy documents, reports, case examples)

- Consultation with YouthREX staff and four coordinators from Carleton University's Enriched Support Program (ESP) and Aboriginal Enriched Support Program (AESP)

\section{Search databases}

- Carleton University and University of Ottawa library databases: PsychINFO, PubMED, Social Work journals, Education Resource Information Centre (ERIC)

- Google and Google Scholar

\section{Search terms:}

Bridging programs, youth, young people, higher education, postsecondary education, underrepresented, access, equity, Ontario, Canada, university, college, courses, pathways, educational attainment, persistence, participation, transition, completion, barriers, implementation, practices, evidence-based

\section{Priority given to:}

- Resources aimed at youth aged 18-25. Where relevant, we also considered youth in primary or secondary school (who are often targeted by early interventions promoting equal access to PSE) and adults over 25 (who often access PSE bridging programs)

- Post-secondary education was defined as universityand college-level programs

- Programs from Ontario, although national and international models that provided supporting evidence are also included

We placed particular emphasis on literature that used multiple research methods such as mixed-methods research studies employing qualitative and quantitative methods. We also looked for studies that included youth and service provider perspectives.

We paid close attention to the differences between access to PSE, persistence in PSE, and completion of PSE to evaluate these different, albeit related, PSE processes.

We also considered the variety of ways bridging programs are conceptualized in the literature and delivered. Therefore, we included some studies that evaluated transition programs, access programs or courses, developmental education or adult education

\section{FEDERAL AND ONTARIO CONTEXT}

The Canadian government has increasingly prioritized access to PSE through a range of initiatives, some targeted at specific groups. ${ }^{6}$ Provincially, the Ontario government

\footnotetext{
Council of Ministers of Education, Canada, 2008; Government of Ontario, 2015; Orders \& Duquette, 2010; see the Additional Resources section for more information on some targeted initiatives
} 


\section{GOVERNMENT INITIATIVES \\ THAT PROMOTE ACCESS TO PSE}

\section{Stepping Up Framework}

The Ontario Ministry of Children and Youth Services has identified Education, Training and Apprenticeships; Employment, Entrepreneurship and Diversity; and, Social Inclusion and Safety as 3 of 7 thematic outcomes areas important for youth wellbeing

\section{Access to Opportunities Strategy}

Ontario's Youth Opportunities Strategy is investing in greater access to opportunities and support initiatives for youth who are marginalized in their communities.

\section{Learn 2020}

Canada's Provincial and Territorial Ministers of Education have provided the Learn 2020 framework to improve Canada's education systems, educational outcomes, and learning opportunities with the goal of contributing to healthy individuals, as well as sustainable societal and economic structures. The Ministers of Education identify four pillars of lifelong learning, one of which is post-secondary education and they are implementing activities to support improved access and outcomes:

- Canada must increase the number of students pursuing post-secondary education by increasing the quality and accessibility of post-secondary education (Council of Ministers of Education, Canada, 2008, p.1). invested over $\$ 100$ million between 2007 to 2008 to improve access to PSE for underrepresented groups through the Access to Opportunities Strategy. This Strategy provides funds for bursaries, access to online learning centres and a variety of one-time access and retention programs targeted to Aboriginal students, Francophone students, first generation students, Crown Wards and students with disabilities. $^{?}$

Norrie and Zhao (2011) report that over 80 percent of secondary school students in Ontario end up enrolling in PSE, and 70 percent of them attain a degree. About half of these students go to university, while the other half enrol in colleges, apprenticeship programs, or private training programs

Ontario's post-secondary institutions compare favourably with post-secondary institutions both across Canada and internationally. ${ }^{8}$ Ontario has:

- the highest university attendance rates in Canada,

- a high proportion of adults with college or university degrees, many with postgraduate degrees, and

- a robust culture of research and development $^{9}$
Where the Ontario PSE system continues to lag is in ensuring access and persistence for underrepresented groups. ${ }^{10}$ For those who do access PSE, access is variable and comes with no guarantee that the student will complete the course of study.

Barriers to participation in PSE fall across of range of challenges including: individual motivation or academic aspirations, parental or family contexts or broader systemic and institutional barriers." While several initiatives exist to meet the needs of students facing these barriers in Ontario, such as the Access to Opportunities Strategy, the overall response has been uncoordinated and fragmented. Institutions have failed to adequately meet the financial and non-financial needs of underrepresented students. For example, there is a lack of programming for advising, counselling, mentoring and providing support to navigate the social and educational aspects of post-secondary institutions. ${ }^{12}$

7 CSA, OSTA, OUSA, 2011

8 Weingarten et al., 2015

${ }^{9}$ Weingarten et al., 2015

${ }^{10}$ CSA, OSTA \& OUSA, 2011; Weingarten et al., 2015

" CSA, OSTA \& OUSA, 2011

${ }^{12}$ CSA, OSTA \& OUSA, 2011 
In the past ten years, PSE participation initiatives and programs have been shifting to promote equal access to PSE rather than simply increasing the number of students enrolling in PSE. ${ }^{13}$

Past initiatives and policies have focused on addressing affordability and financial factors that impact access, ${ }^{14}$ but even with improvements to financial aid in Canada, the gap in access between groups has remained the same over time. This has important implications for the design and delivery of programs and policies addressing equal access to PSE. There is consensus that population-wide financial aid programs such as family savings incentives are designed to subsidize PSE participation of middle- and upper-income students who are likely already accessing PSE; however, such programs and incentives have little impact on access and persistence rates for underrepresented youth. ${ }^{15}$ Government, institutional, program, and research-based responses aimed at improving accessibility to post-secondary education have failed to adequately consider the unique contexts and needs of underrepresented groups. ${ }^{16}$ Their responses have too often focused on financial aid and have not taken into account the complex range of barriers affecting a young person's participation in post-secondary education.

There is also a clear consensus that the traditional view that the primary barrier to PSE participation is financial does not accurately reflect the realities of underrepresented groups. ${ }^{17}$ For example, a student from a low-income family might have difficulty accessing PSE because of lack of funds, but coming from an under-resourced secondary school combined with living a distance away from any PSE institution could also affect his or her ability to participate in PSE. These factors are complicated even further by the fact that the opportunity to participate in PSE also depends to some extent on early life experiences in elementary and high school. ${ }^{18}$ Additionally, research consistently finds that cultural factors, such as parental engagement and encouragement, have a greater impact on access and persistence in PSE than financial factors. In fact, cultural factors can affect a student's interest in and attitude toward PSE long before admission to a PSE institution. ${ }^{19}$

Research has started to create a complex picture of PSE participation by mapping out how factors that are relevant at different times in a student's life affect his or her decision and ability to access PSE. It looks at processes, factors, and "critical transitions" (periods of time during which a student makes important decisions related to PSE that affect their access and persistence in PSE, such as during the application process for PSE) that can serve as opportunities to develop and deliver targeted interventions. ${ }^{20}$

CSA, OSTA \& OUSA (2011) used a combination of focus groups held with low-income, rural and northern, firstgeneration, and Aboriginal students, along with a review of the literature and consultations with experts to develop a comprehensive holistic strategy for improving PSE accessibility in Ontario. The strategy that they developed, aimed at program and policy decision-makers, called for a re-conceptualization of access to PSE that would respond effectively to the complex interplay of barriers that underrepresented groups face from an early age. Their recommendations include the implementation of six options for improved programming: (a) early outreach programs,

\footnotetext{
${ }^{13}$ Finnie et al., 2008

${ }^{14}$ Finnie et al., 2008; Finnie et al., 2012

${ }^{15}$ Finnie et al., 2008

${ }^{16}$ Finnie, Sweetman, \& Usher, 2008; Finnie et al., 2012

\footnotetext{
${ }^{18}$ CSA, OSTA \& OUSA, 2011; Deller \& Thomas, 2013; Norrie \& Zhao, 2011

${ }^{19}$ Finnie et al., 2008

${ }^{20}$ CSA, OSTA \& OUSA, 2011; Finnie et al., 2008; Finnie et al., 2012; Solorzano,
} Datnow, Park, \& Watford, 2013 
Research has started to create a complex picture of PSE participation by mapping out how factors that are relevant at different times in a student's life affect his or her decision and ability to access PSE. 
(b) outreach in primary and secondary schools, (c) pathway mobility (fluid movement between any one of employment, training, college and university, for example, through credit transfer programs between college and university), (d) financial assistance, (e) online access to PSE credentials and $(f)$ institutional support.

CSA, OSTA \& OUSA (2011) proposed strategy aligns with a well-established body of research that considers equity in PSE participation to involve three process dimensions: access (before PSE entry), persistence (throughout studies) and attainment (completion of PSE credentials). ${ }^{21}$ Access is only part of the story. ${ }^{22}$

\section{EQUITY IN PSE PARTICIPATION: WHO IS UNDERREPRESENTED}

\section{Review of PSE participation by underrepresented groups}

While PSE is linked with both short- and long-term

outcomes of personal and societal health and wellbeing, not all youth in Canada have equal access to its benefits. A large body of research shows that certain groups of youth face multiple barriers preventing them from accessing and participating in PSE. ${ }^{23}$

This literature has found that young people with the following characteristics have lower PSE participation rates:
(a) comes from a low-income family
(b) is the first person in his or her family to attend PSE (first generation)
(c) is Aboriginal
(d) is from a rural area, or from the North
(e) has dependents
(f) has disabilities
$\mathrm{g}$ ) is a young person in or leaving government care (Crown Ward)

Other factors such as gender and race have also been shown to affect a person's chance of participating in PSE. Finnie et al. (2012) aimed to better understand the rates at which underrepresented PSE student groups in Ontario and across Canada persist in their studies and eventually attain PSE credentials. They drew on the Youth-in-Transition-Survey-A (YITS-A) developed jointly by Statistics Canada and Human Resources and Skills Development Canada for data on both the general student population attending PSE and underrepresented students.

This survey considers the many routes students may take toward attaining a PSE degree or diploma. Students might leave certain institutions and attend others, drop out of PSE altogether, switch programs, continue in the same program, or end up graduating through any one of these paths.

Finnie et al. (2012) found that, on a national scale, students with disabilities and students from low-income or singleparent families are more likely to drop out of their PSE studies compared to students without these characteristics.

Students who are the first in their family to attend university (i.e., first-generation students), Aboriginal students, students with disabilities, students from rural backgrounds, and students from low-income or single-parent families also have high rates of leaving their university-level studies.

Weingarten et al., too, found that a relatively low number of first-generation students access PSE. Drawing from the Statistics Canada Survey of Labour and Income Dynamics (SLID) data collected between 2009 and 2011, they found that only $40 \%$ of young people aged $18-24$ who would be the first in their family to attend college or university did attend PSE.
${ }^{21}$ Finnie et al, 2008

${ }^{22}$ Tinto \& Pusser, 2006

\footnotetext{
${ }^{23}$ College Student Alliance Toronto [CSA], Ontario Student Trustees' Association [OSTA] \& Ontario Undergraduate Student Alliance [OUSA], 2011; Dworsky \& Smithgall, 2014; Educational Policy Institute, 2009; Finnie, Childs, \& Qiu, 2012; Norrie \& Zhao, 2011; Orders \& Duquette, 2010; Weingarten et al., 2015
} 
Aboriginal students continue to show the highest rates of dropping out of PSE before they can complete their studies, ${ }^{24}$ and across the country, the number of Aboriginal students attaining diplomas and degrees is low. ${ }^{25}$ Norrie \& Zhao (2011) found that Aboriginal identity and parental education correlate most significantly with Aboriginal students leaving PSE. CSA, OSTA and OUSTA (2011) report that Aboriginal students may face substantial financial and non-financial barriers that contribute to significantly lower rates of leaving PSE. Inadequate financial resources and the need to work during PSE have been cited as the main reasons why Aboriginal students leave PSE. A wide range of other factors combine with these barriers, including low family income or lack of parental education, avoidance of high levels of debt, lack of available band-administered funding (in particular for non-status students), family responsibilities, distance to PSE, low employment related to PSE studies in home communities and conflicts between Aboriginal cultural beliefs and mainstream post-secondary institutions. ${ }^{26}$

Weingarten et al. (2015) found it difficult to clarify the rates of PSE completion for Aboriginal students living both on- and off-reserve. National Household Survey data in 2006 and 2011 census data has been used to evaluate PSE participation, but this data has shown conflicting results for the Aboriginal population. There have also been problems with data collection processes. These have resulted in Aboriginal students' experiences being underreported in the 2006 census. Overall, people who identify as Aboriginal between the ages of 25 and 64 years of age show very low rates of having ever attained university, college and/or trade credentials. The data also suggests that Aboriginal students are more likely to attain college and trade credentials than university degrees.
Research has also pointed to some misconceptions about participation rates of particular groups of students. Contrary to common perceptions, Finnie et al. (2012) found that firstand second-generation immigrants and Francophone students outside of Quebec have rates of leaving their studies that are similar to or lower than other groups. In addition, these groups are more likely to register for and attend university than nonimmigrants, but they are less likely to enrol in other forms of PSE, such as college or trade programs. ${ }^{27}$

Some evidence has shown that certain first and second generation ethnic groups, including students of Caribbean, Latin American and East African descent have lower levels of participation in PSE compared to Canadian-born students. ${ }^{28}$ A combination of lower socio-economic status, discrimination within educational institutions and feelings of alienation among visible minority groups may all contribute to higher drop-out rates and lower levels of PSE achievement. ${ }^{29}$

While the gap between genders enrolling in different forms of PSE is decreasing, females are still more likely to enrol in any form of PSE (including university), while males are more likely than females to enrol in trade or college programs. ${ }^{30}$

Norrie and Zhao (2011) found that when family status (i.e. single-parent families) and native language are considered in combination with all other underrepresentation-related factors (i.e., low income, first-generation PSE student, rural, Aboriginal, or person with a disability), students who are from single-parent families or who speak a native language other than English are no longer significantly underrepresented compared to rates of the general student population. They also found that the effect that having a low income has on PSE access decreases when considered in combination with other factors.

\footnotetext{
${ }^{24}$ Finnie et al., 2012; Norrie \& Zhao, 2011

${ }^{25}$ Weingarten et al., 2015

${ }^{26}$ CSA, OSTA \& OUSTA, 2011

${ }^{27}$ Norrie \& Zhao, 2011
}

${ }^{28}$ CSA, OSTA \& OUSTA, 2011

${ }^{29}$ CSA, OSTA \& OUSTA, 2011

${ }^{30}$ Norrie \& Zhao, 2011 


\section{BARRIERS TO PSE PARTICIPATION}

Bridging programs are an opportunity to respond to the primary factors that present barriers to PSE participation. Literature on this topic tends to group these factors into financial, informational, and motivational barriers, while paying less attention to academic, geographic, and institutional factors. ${ }^{31}$ Additionally, researchers have suggested that PSE access and completion strategies would be more effective in identifying students at risk of noncompletion by looking at high school and PSE academic records, student attitudes or feelings towards school and parental encouragement. ${ }^{32}$

Norrie and Zhao (2011) developed the following framework now commonly used in the literature to encompass all the known barriers to participation in PSE:

- Financial - lack of funds, debt aversion in a loan-based student aid system, sensitivity to the increasing cost of attending PSE

- Informational - lack of financial and post-secondary pathway information

- Motivational - lack of confidence, absence of parental engagement and encouragement, lack of adequate preparation for PSE in primary or secondary school environment

A crucial analytic strategy used across studies on bridging programs is that researchers tend to put people into groups according to single characteristics (e.g. these students are low-income, these students are Aboriginal), however, when group characteristics are considered holistically (e.g., these students are low-income and Aboriginal), their participation rates can differ than when fragments of people's identities are analyzed separately.

This research suggests that when designing an intervention, it is more effective to consider several group characteristics in combination instead of focusing on a single characteristic. ${ }^{33}$ The evidence, however, is limited because the majority of research on the topic analyses student experience according to single characteristics (e.g., students from low-income families, rural students, students with disabilities). While multi-characteristic disaggregation is complex, the reality is that one student from an underrepresented group may experience diverse and overlapping issues that shape their access to and participation in PSE and these should be considered in combination.

Table 1 uses existing research to show the relationship between barriers to PSE participation and underrepresented groups. For example, the evidence shows that firstgeneration students experience financial, informational, motivational, and institutional barriers to PSE participation. However, a relationship between first-generation students and geographic barriers to PSE has not been found, nor is there any information on academic barriers. Understanding the complex interrelationship of factors that present barriers to PSE for underrepresented groups is the first step in targeting these students' needs.

Bridging programs are uniquely positioned to use this framework, given that they (a) usually operate within postsecondary institutions; (b) offer services that connect institutions, families, and communities, and (c) can be developed to adapt to the local realities of students. Institutions can conduct needs assessments and collect data to understand how various groups of barriers affect students in their local communities. Collecting data on how observable characteristics, attitudes, and interests contribute to these barriers and using this data may be a more effective strategy for program development than simply targeting specific groups. ${ }^{34}$

\footnotetext{
${ }^{33}$ Educational Policy Institute, 2009; Finnie et al., 2012; Finnie et al., 2008; Norrie \& Zhao, 2011
}

${ }^{34}$ Educational Policy Institute; 2009; Finnie et al., 2012 
TABLE 1

KNOWN RELATIONSHIPS BETWEEN BARRIERS AND VARIOUS SOCIO-DEMOGRAPHIC CHARACTERISTICS

\begin{tabular}{|c|c|c|c|c|c|c|}
\hline \multirow{2}{*}{ Group } & \multicolumn{6}{|c|}{ Barriers } \\
\cline { 2 - 7 } & Financial & Informational & Motivational & Academic & Geographic & Institutional \\
\hline Low-Income & $\checkmark$ & $\checkmark$ & $\checkmark$ & $\checkmark$ & X & $\checkmark$ \\
\hline First Generation & $\checkmark$ & $\checkmark$ & $\checkmark$ & $?$ & X & $\checkmark$ \\
\hline Aboriginal & $\checkmark$ & $\checkmark$ & $\checkmark$ & $\checkmark$ & $\checkmark$ & $\checkmark$ \\
\hline Rural/Northern & $\checkmark$ & $\checkmark$ & $\checkmark$ & $x$ & $\checkmark$ & $\checkmark$ \\
\hline With Dependents & $\checkmark$ & $?$ & $?$ & $\checkmark$ & X & $\checkmark$ \\
\hline Gender & X & $?$ & $\checkmark$ & $\checkmark$ & X & $?$ \\
\hline Race & $\checkmark$ & $?$ & $\checkmark$ & $\checkmark$ & X & $\checkmark$ \\
\hline
\end{tabular}

Source: Retrieved from CSA, OSTA \& OUSA, 2011, p.18

\section{BRIDGING PROGRAMS: ADDRESSING BARRIERS TO POST-SECONDARY EDUCATION PARTICIPATION}

It is clear that underrepresented students in Ontario continue to face multiple barriers to accessing, participating, and completing their PSE studies. Bridging programs have the potential to respond to the many and often overlapping challenges underrepresented youth face by providing individualized and alternative assistance and pathways for them to gain entry to PSE, persist through their studies, and attain PSE credentials.

Bridging programs provide an alternative pathway for students who have been disadvantaged in gaining the skills, requirements, or prerequisites to participate in PSE. These programs focus on supporting young people during their transition from college, employment, non-employment, high school, or adult education to their desired form of PSE. They assist students in gaining academic and social skills, navigating social and academic systems and supports of PSE institutions, accessing additional institutional and community support, and ultimately achieving the necessary credentials or course requirements to enter, persist, and complete a PSE program. Bridging programs are most often hosted by post-secondary educational institutions and are a result of collaboration with secondary schools, employment services, and community organizations. Programs vary in structure, affiliation with PSE institutions, policies, and processes. Bridging programs provide information on admissions, financial support, and guidance to students in PSE institutions. They also support students in exploring how they can pursue career and academic goals, which can build their self-confidence and skills. ${ }^{35}$

Some programs offer career-focused support to link their studies to long-term labour market participation. Other programs target particular populations and their specific 
needs in terms of PSE participation. ${ }^{36}$ For example, Aboriginal-focused programs adapt transition supports to the unique needs and strengths of Indigenous communities. ${ }^{37}$

One of the challenges facing bridging program administrators and staff, bridging program developers and evaluators, researchers, and policy-and decision-makers is the lack of consensus in the literature on the definition of bridging programs and their features. ${ }^{38}$ Institutions use a wide range of terms including bridge or bridging programs, foundation education or studies, bridging education, introductory or entry-level studies, access education, remedial education, development education, and gateway or training opportunities. Moreover, some programs discussed in the literature focus on bridging or access courses designed to enhance a specific subject area, such as mathematics.

The term bridging is used because all of the programs have a specific bridging function. They "bridge" students into first year PSE programs. Benseman \& Russ (2003) state that because bridging programs are often developed in local contexts rather than at a national level, they vary in their structures and functions. For example, in the United
States, Solorzano et al. (2013) describe how "development education" is replacing the terminology of "remediation courses" to refer to classes or activities within community colleges that meet the needs of students who dot not have the skills, experience or orientation that are recognized as necessary to participate in and succeed in PSE. However, some countries have a national program that have bridging functions. For example, in England and Wales there is an Access to Higher Education Diploma that targets underprepared students (visit this link for a review of the program: https://www.accesstohe.ac.uk/Access/About/ Pages/Default.aspx.)

While the breadth and variation in terminology can make for some confusion, researchers who study bridging programs in the United States have found that variation in program implementation is necessary to adapt to local realities. ${ }^{39}$

\footnotetext{
${ }^{36}$ Brathwaite, 2003; Solorzano et al., 2013

${ }^{37}$ Wesley-Esquimaux \& Bolduc, n.d.

${ }^{38}$ Benseman \& Russ, 2003; Bragg et al., 2011

${ }^{39}$ Bragg et al., 2011; Price \& Roberts, 2015
} 


\section{CARLETON UNIVERSITY'S}

ENRICHED SUPPORT PROGRAM (ESP) AND ABORIGINAL ENRICHED SUPPORT PROGRAM (AESP)

Community consultation to inform this report was conducted with representatives of Carleton's ESP and AESP to understand one local experience of implementing a bridging program.

The ESP program, in operation since 1996, is intended for students who do not meet traditional PSE entrance requirements. Students take first-year university credit courses specified by their desired stream of study (i.e. science, business, arts and social sciences, or engineering), while drawing on a combination of additional support including; (a) workshops to assist with credit courses, (b) academic coaching in one-on-one sessions, and (c) academic advising for help with navigation, admissions, referrals, goal-setting and personal experiences. The four academic streams offer various pathways for entering and persisting in a degree program. There is also a mentorship component, where students who have already participated in the program can provide various forms of academic and personal support to current students. Student ambassadors help with recruitment and outreach in high schools.

The AESP is identical to the ESP, but offers additional support including (a) a course on Indigenous issues, (b) an Aboriginal mentor, and (c) connections to local Indigenous organizations and communities. AESP staff and faculty work in collaboration with Carleton's Centre for Aboriginal Culture and Education (CACE) to conduct outreach on reserves and to carry out school-based programs to showcase what Carleton offers. Importantly, they offer friendly support to help students cope with the day-to-day reality of university life. Partnerships with the local colleges and universities also strengthen bridging efforts.

Institutional support has contributed greatly to student success in Carleton's ESP and AESP programs. This support includes working with departments to save spots in classes for program participants. However, there are still policy and system-level requirements that serve as barriers. For example, some Aboriginal bands will not fund transition year programs for Aboriginal students who need financial support. In addition, government financial assistance programs and provincial standards sometimes restrict students from accessing support from the program by providing insufficient resources and/or having conflicting requirements.

\section{Lessons Learned}

- Creating a non-judgmental and safe space for students in the classroom and in the general university environment helps them feel comfortable and connected.

- Responding to the needs of students who have challenges with being underprepared and lacking motivation is important. Workshops use different instruction approaches to match student preparedness. Despite this, the wide range of academic preparation students need is a challenge to adapt to. As students progress through the year, workshop facilitators provide them with more choices of activities (in the classroom), which enhances their sense of autonomy and their ability to work independently the following year, after they are admitted to their degree program.

- Working with other support systems throughout the university and in the community, including health and counselling and Aboriginal-focused supports, is necessary. Both programs require personalized support and involvement in the lives of students to keep them engaged and to ensure that the program continues to serve their needs. Reaching out to students and tracking their attendance are a part of the task.

- Communicating and getting the word out about these types of programs is a challenge. Programs can be confused with other access or bridging opportunities and they are still an emerging practice.

- Keeping students engaged and motivated throughout the year is the main challenge.

- Designing a program should involve building students' understanding of academic discourse, such as how to access and analyze information in the particular discipline. Support workshops should integrate learning study skills with reviewing course content rather than offering stand-alone classes on study skills.

- Student facilitators of course-specific workshops are more successful when they have previously taken the course they are facilitating and have succeeded academically in it. There should be extensive training for facilitators, including how to effectively practise learning theory and how to integrate learning strategies appropriate to their own discipline. 


\section{3 // DESIGNING BRIDGING PROGRAMS}

\section{EVIDENCE-BASED STRATEGIES}

Research on bridging programs and courses with bridging functions shows that such programs can help underrepresented and/or underprepared students both with accessing PSE and building positive personal and professional skills that will help them persist toward completion of their studies.

\section{ASSESSING THE EVIDENCE FOR BRIDGING PROGRAMS}

The evidence available to assess promising interventions in the Canadian context is limited. As Miner (2011) notes, concerns about equitable access to PSE for underrepresented groups have only become issues of social policy relatively recently. There has been little systematic research on either the processes or outcomes of PSE bridging programs in part because of lack of funding and also because of the complexity of the issues these programs address, and the range of services they offer. Moreover, collecting comparison and control group data presents ethical challenges. ${ }^{40}$ In a report that assesses bridging programs in the Greater Toronto Area prepared for the Council of Educators of Toronto, Miner further concludes: "research involving longitudinal data is lacking with regard to [bridging] programs and in both Canada and the United States responsible authorities have explicitly shied away from endorsing different practices for different target groups". ${ }^{41}$ There is an ongoing need to support research initiatives that evaluate the impact of bridging programs. Post-secondary institutions are still struggling with developing (a) well-defined indicators of PSE access based on equity, and (b) systematic and reliable processes to collect and evaluate data on the underrepresentation of certain student populations for whom bridging programs can be developed.

Because few PSE bridging programs have been rigorously researched or evaluated, the majority of information available in Canada is descriptive and located in individual reports from PSE institutions. PSE bridging programs could greatly benefit from research assessing their outcomes and impact. Many of these programs are underfunded and lack the capacity to undertake long-term program evaluation. Miner identified the following challenges to understanding the impact of Canadian PSE bridging programs: short timelines and project-based funding, lack of core funding, high staff turnover, and funding for programming and not core costs or evaluation. ${ }^{42}$ Despite the limitations Miner identifies, he presents promising practices related to five groups facing barriers to PSE access, persistence, and completion with a recognition that students often face multiple overlapping and intersecting barriers: Aboriginal students, first-generation students, low-income students, students with disabilities, immigrants and visible minority students.

The evidence in favour of bridging programs is still preliminary, but models of such programs exist and should be studied further and expanded upon. Some select Ontario examples include Ryerson's Bridges to Ryerson, Tri-

Mentoring, and Road to Ryerson programs, ${ }^{43}$ the University of Toronto's Transitional Year Programme, York University's Transition Year Program, Carleton University's Enriched Support Program and Aboriginal Enriched Support Program, and many more.
${ }^{40}$ Miner, 2011

${ }^{41}$ Miner, 2011, p. 6

\footnotetext{
${ }^{42}$ Miner, 2011, p. 16

${ }^{43}$ Malik, Guan, Vetere, Abramovitch, 2011
} 
Given this context we present promising research drawing on international case studies that demonstrate the potential impact of PSE bridging programs. Given the scope of this report, we do not include a review of early prevention programs. The examples we draw on were selected because the program outcomes have been evaluated and the results have been published. Moreover, they demonstrate a range of models and interventions that have promising practice implications.

An evaluation of bridging programs conducted in three states (Illinois, Minnesota and Wisconsin) that participated in the Shifting Gears Initiative, [see Appendix 2] showed promising outcomes after eight years of program implementation. The three states collected program participant data between 2011 and 2014 to evaluate how well participants fulfilled three expected outcomes: i) enrolling in a post-secondary program of study; ii) earning credits and credentials; and iii) gaining employment.

The Shifting Gears Initiative aims to systemically influence and bring together adult education, PSE, and workforce development policies to improve economic and educational outcomes for low-skilled or underprepared workers. While programs were not specifically designed for population groups such as Native Americans or students from any particular socioeconomic background, they offer an institutionally supported alternative pathway to participate in PSE for those who are not able to access PSE because of gaps in their skills or credentials.

Of the seven states that originally participated in the initiative, Illinois, Minnesota, and Wisconsin have demonstrated positive progress with their bridging efforts. While each of these three states developed state-level definitions for their programs to reflect the state's unique needs, all definitions reflected the goal to "prepare adult basic education learners to successfully transition to post- secondary education". 44 The local programs were designed to be a primary transition path for people with low occupational and educational skills. They would first receive basic PSE prepatory education and then move into a credit-based post-secondary program. Each of the states used an overarching "career pathway framework," which emphasized the attainment of credentials with economic value (see the Alliance for Quality Career Pathways Framework 1.0 for more information).

The Shifting Gears Initiative findings as well as findings from other evaluations of bridging programs and courses ${ }^{45}$ suggest a number of potential outcomes that can be achieved when program and institutional support is put in place (see Section 4 below, Moving the Dial: Recommendations for Practice).

Such outcomes include:

- Enrolment in PSE programs of study

- Development of personal and professional skills for persisting in PSE

- PSE credits and credentials earned

- Employment

Bragg et al. (2009) found that four elements were associated with program completion for bridging program students:

1. Receiving career orientation counselling (employer visits, training program presentations and other career support) more than once

2. Receiving admission and financial assistance (individualized assistance with admissions processes or completion of financial aid applications) at least once

3. Receiving advising (career advising or coaching, academic advising or other related advising services) at least once

4. Receiving transportation assistance (provision of bus tokens, cab reimbursement, gas cards or mileage reimbursement) at least once 
The Illinois and Minnesota bridging programs of the Shifting Gears Initiative have demonstrated that three critical program components can be replicated across many different forms of program implementation. ${ }^{46}$ While the strategies and techniques of each site varied to adapt to differences in local cultural context, institutional policies, and/or workforce requirements, all the program developers consistently included the following critical components:

- Contextualized instruction that integrates basic reading, math, language skills, and industry/occupation knowledge

- Career development that includes career exploration, career planning within a career area, and understanding the world of work

- Transition services that provide students with the information and assistance they need to successfully navigate the process of moving from adult education or remedial coursework to post-secondary credit or occupational programs 47

Burns et al.'s (2013) analysis of the Minnesota FastTRAC bridging programs found that in addition to the above the three critical components, successful programs also include:

(a) strategies such as interviews or data collection to ensure participants recruited are appropriate for the program, which may require balancing needs such as low-income and low skills with testing scores

(b) intentional recruitment strategies

(c) well-developed partnerships with employment sectors, educational institutions or government

(d) post-secondary credits to students

(e) programs that are adapted to local needs and realities

(f) data tracking systems for monitoring progress and evaluating outcomes

(g) appropriate funding

(h) strategic plans to ensure sustainability over time
Finally, better outcomes are also associated with more frequent interaction with an assigned transition coordinator and with more transportation assistance. A transition coordinator is vital for helping students navigate, advocate for, and coordinate with the support services and the many PSE college services. Competencies for this role include an in-depth knowledge of working with diverse youth and adult student populations, and knowledge of a wide range of college and community services.

\section{FACILITATING PSE PERSISTENCE AND COMPLETION}

Accessing PSE is only one dimension of the challenge to equitable outcomes bridging programs address. Once students enter PSE, they need to develop skills to succeed within their program and complete their course of study.

Bridging programs can support students to build their selfconfidence, determination, and commitment to fulfilling their education and career goals. A study from the United Kingdom that explored the experiences of marginalized Black students enrolled in further education (FE) access courses that led to entrance into an undergraduate social work program. The study sought to better understand the barriers these students faced in navigating the post-secondary education system and the usefulness of the access program. ${ }^{48}$ A total of 55 students completed questionnaires, 21 participated in initial focus groups, 13 were involved in follow-up focus groups, and 4 students and 3 course tutors participated in one-on-one interviews. The average age of the participants in this study was 32 , with $78 \%$ of them being women.

Study results found that greater attention needs to be paid to the unique life experiences of students in relation to the selection process for the undergraduate social work program,

${ }^{47}$ Bragg et al., 2009, p.74 
the development of the course curriculum, and the classroom culture in the bridging program. Two other elements were considered important to the bridging program's success: (a) fostering a culture of learning that offered informal social and academic support and allowed for the recognition of each student's unique life experiences, and (b) having some tutors from similar racial and ethnic backgrounds as the students.

In 2008 researchers associated with the University of California All Campus Consortium on Research for Diversity (US/ACCORD) launched a Pathways Project study designed to determine the critical areas of intervention with lowincome youth to ensure their PSE success. ${ }^{49}$ Solorzano and colleagues interviewed 308 students (mostly students of colour), faculty, and staff at two colleges and one high school in California, United States that delivered targeted bridging programs. In addition, they reviewed the programs' documentation. The main findings from this study include that students viewed the knowledge, information, and personal support they received from advisors or counsellors as critical to bridging gaps in their ability to navigate available resources, plan their academic and career pathways, and find support when personal circumstances blocked them from continuing their studies. ${ }^{50}$ They also cited tutoring as important to student success in their academic pathways.

Another study, from an Australian university, used email interviews to assess how 15 students and 10 teachers/ coordinators who participated in a mathematics bridging course perceived that course. ${ }^{51}$ These mathematics bridging courses consisted of 40 hours or less of intensive course instruction before the start of a PSE academic year and usually involve students who have left high school and require more skill in mathematics to move on to further studies.

Here, too, the supportive learning culture between peers and between students and teachers was a valuable component of the program, and included group discussion and group problem solving. These bridging courses resulted in students (a) improving their attitude toward math, and (b) gaining math skills that they viewed, in some cases, as transferrable to their careers. Moreover, students generally found the bridging course valuable as a transition support allowing them to experience what university would be like.

Essack \& Quayle (2007) explored the perspectives of nine Black South African students who participated in an access program for students who did not meet traditional university entrance requirements but were now successfully enrolled in degree studies. Many of them spoke English as their second language. They had participated in this program for one year and, overall, attributed their access to and success in university to the program because it helped them develop a range of academic and social skills necessary for mainstream PSE studies. One recommendation by the authors for improving courses in this program was to avoid problem-or deficit-based language that framed students as inferior, thereby stigmatizing them. The study also raised concerns that not recognizing the diversity of students and grouping them instead into a single category of "disadvantaged" could also be stigmatizing.

Delivering a bridging program effectively requires recognizing the diverse identities and life experiences of students within the actual classroom. Both the curriculum and the learning environment should draw on adult education principles in adapting to these unique contexts and life experiences. ${ }^{52}$ Additionally, using strengths-based language has been cited as one way to foster a positive learning experience. ${ }^{53}$ Lessons learned from the Transitional Years Programme in Toronto include creating an interactive and informal learning environment that (a) uses ongoing student teacher and peer-peer dialogue, and (b) embeds equity and

\footnotetext{
${ }^{49}$ Solorzano et al., 2013

50 Solorzano et al., 2013

${ }^{51}$ Gordon \& Nicholas, 2013
}

\footnotetext{
52 Abramovitch, 2003; Brathwaite, 2003; Dillon, 2012

${ }^{53}$ Dillon, 2012

${ }^{54}$ Abramovitch, 2003; Brathwaite, 2003
} 
empowerment into the curriculum. ${ }^{54}$ Encouraging students to re-affirm their personal identity, culture, traditions, and beliefs can give them the confidence and skills to critically engage with their studies and with the institutions around them. ${ }^{55}$ For Abramovitch, the ideal is not to assimilate the student into a particular mainstream model, but to build his or her skills for critically evaluating, navigating, and accessing the appropriate resources needed to personally succeed.

\section{Institutional support for bridging programs}

An important lesson learned from implementing various bridging programs is that institutional support and/or institutionalizing the programs is crucial to their ongoing success and sustainability. ${ }^{56}$ This means that PSE institutions must not only provide adequate resources to develop a comprehensive program, but that the commitment to principles of equity must be integrated into the institution's mission and values on the part of students, staff, administration, and leaders. ${ }^{57}$

Price and Roberts (2015) summarized some of the essential factors that support the success and sustainability of the Shifting Gear's bridging programs in Illinois, Wisconsin, and Minnesota:

- Involvement and commitment on the part of senior leadership across partner agencies in employment, education, government or community. System-level and leadership commitment can help both to influence governmental policy changes and to leverage external resources.

- Identification of goals and plans to expand both the scope and number of bridging programs and the number of participants. Bridging program teams need to assess the need for these programs and to develop strategies and goals that can increase the capacity of the programs to respond. However, without external support to offset limited resources, it can be difficult to expand the impact and sustainability of these programs.
- Acknowledgment that institutional and government policies must change and adapt to meet the resource needs of bridging programs.

- Providing targeted, ongoing professional development for bridging program staff, administrators, etc., which can attract community and institutional support for these programs.

- Using data to promote the development and adoption of bridging programs by PSE institutions. Ongoing data collection and analysis is crucial for demonstrating the progress and positive impact of these programs. However, accomplishing this can be difficult without internal expertise in data collection and use.

Local capacity and resources, especially funding, seem to be one of the greatest barriers to the implementation of bridging programs. ${ }^{58}$ For example, external funding and technical assistance in data collection and analysis were key support elements for the first few years of the Shifting Gears project. The funding allowed specific bridging programs to expand, and the technical assistance helped the programs to develop expertise in the areas of data collection and analysis as well as the creation of effective communication strategies.

The challenge of securing buy-in from many different stakeholders was a common theme not only in the various Shifting Gears initiatives, ${ }^{59}$ but also in Carleton University's Enriched Support Program, especially in terms of delivering the message of the benefits, usefulness, and holistic approaches of bridging programs. Recruiting and retaining students has also been cited by bridging service providers as a particular challenge for these programs. ${ }^{60}$

While partnerships are crucial to the success of bridging programs, Minnesota found that lack of clarity regarding the role and responsibilities of each partner combined with communication problems between the partners can cause challenges within these partnerships. ${ }^{61}$

\footnotetext{
55 Abramovitch, 2003

${ }^{56}$ Benseman \& Russ, 2003; Brathwaite, 2003; Price \& Roberts, 2015

${ }^{57}$ Brathwaite,2003

${ }^{58}$ Benseman \& Russ, 2003; Price \& Roberts, 2015; The Joyce Foundation, 2013
}

\footnotetext{
59 Price \& Roberts, 2015; The Joyce Foundation, 2013

${ }^{60}$ Benseman \& Russ, 2003

${ }^{61}$ The Joyce Foundation, 2013
} 


\section{4 // MOVING THE DIAL - RECOMMENDATIONS FOR PRACTICE}

While data on bridging programs is still emerging, current findings demonstrate the potential of these programs in addressing systemic problems that affect young people's ability to succeed in PSE and ultimately in the labour market

This means that change should be systemic as well, including matching the development of governmental and institutional, educational, and employment policies to the needs of underrepresented students who require bridging programs to help them access PSE.

The research suggests that local educational institutions should offer bridging programs that integrate access to PSE credit courses with adult basic education courses. Allowing students in such programs to attain credit from the program itself seems to have a major impact on student participation in further PSE studies. ${ }^{62}$ Bridging programs seem to be particularly beneficial to English as a Second Language (ESL) students, although this evidence is not conclusive. ${ }^{63}$

Programs may also be more beneficial for students when these programs adapt to local contexts, and take into account possible career pathways, student demographics, and recognize the diversity of student experiences and the unique challenges of students who have low-income backgrounds, are underprepared for studies, and who have particular cultural or language needs. ${ }^{64}$

PSE bridging programs may have greater success in supporting students when they offer holistic and ongoing support services that address both the financial and the nonfinancial needs of the students. ${ }^{65}$
Some of the content critical to successful bridging courses includes:

(a) academic and career planning;

(b) tutoring in course content;

(c) navigating PSE, PSE admissions, and community resources; and,

(d) assistance with additional personal, social, and academic support.

The role of a transition coordinator was highlighted as a crucial support service as long as this person has the ability to respond to diverse young adult needs along with a good knowledge of institutional and community services.

The literature offers a number of practices, strategies, and key factors for success to improve the development and implementation of bridging programs. In particular, the system-wide implementation of the Shifting Gears Initiative presents a promising evidence base that can be replicated by other bridging programs.

It is important to invest in resources and strategies to develop bridging programs that benefit from the system integration, collaboration, and coordination of Ontario-based educational institutions, employers, government policy-makers, and bridging program decision-makers.

Based on our review of the literature, we offer the following recommendations:

\footnotetext{
62 Minnesota State Colleges and Universities, 2013; Wisconsin Career Pathways, 2015

${ }^{63}$ Wisconsin Career Pathways, 2015

${ }^{64}$ Dillon, 2012; Essack \& Quayle, 2007
}

${ }^{65}$ Bragg et al., 2009; Gordon \& Nicholas, 2013; Dillon, 2012

${ }^{66}$ Solorzano et al., 2013 


\section{RECOMMENDATION 1}

Local PSE institutions should offer bridging programs that include contextualized instruction, career development, and transition services. Bridging programs should be adapted to local contexts, institutional policies, and workforce requirements.

In Canada and around the world, the wide range of approaches to implementing bridging programs can make it difficult to isolate the core elements of program development. However, the literature shows that successful programs usually focus on skill development, course content support, transitional and/or navigational support, and career and/or academic planning. Within these broad categories, models vary in their use of instructors, mentors, advisors/ counsellors, and coaches to assist in the transition process.

\section{RECOMMENDATION 2}

Bridging programs should provide ongoing holistic support that includes counselling, addressing a range of financial and non-financial needs.

Advisors or counsellors play a critical role in supporting underprepared students in understanding how to navigate post-secondary institutions, apply for programs of study, plan academic and career goals, and access support, such as financial and non-financial resources, for personal circumstances. ${ }^{66}$ Tutoring is another important academic support for helping students succeed in their academic pathways.

Providing students with more career counselling, financial and admissions assistance, advising, and transportation assistance contributes to better outcomes. ${ }^{67}$ In addition, a learning environment with peers who can offer emotional and social support is also important for student engagement and participation in bridging programs. ${ }^{68}$

\section{RECOMMENDATION 3}

Bridging programs should recognize and respond to the diversity of students' needs and experiences.

The learning curriculum, classroom environment, and overall institution should work to encourage students' abilities to understand equity and use this perspective to be critical of their environments, and seek to empower and develop confidence and skills in students participating in bridging programming.

Responding to the diversity of students' needs is linked to a bridging program's success, although this can be a challenging process because the student body can have a wide range of life experiences and levels of preparedness. ${ }^{69}$

\section{RECOMMENDATION 4}

PSE institutions should provide institutional support and resources to effectively meet the needs of students requiring bridging programs.

PSE institutions should work with their partners, such as employment sectors or other educational institutions, to conduct local needs assessments so they can design and deliver bridging programs that can respond to and counter the barriers faced by underrepresented youth. PSE institutions should articulate and practise their commitment to principles of equal access by supporting bridging program efforts.

\section{RECOMMENDATION 5}

Educational, government, and employment institutions should work collaboratively with bridging programs to develop and provide funding, resources, expertise, and implementation supports.

Institutional and cross-sectoral support and investment is crucial for the success and sustainability of bridging programs. 


\section{RECOMMENDATION 6}

Additional research and evaluation is needed to expand the evidence base related to understanding successful bridging program processes, outcomes and impacts.

Government, research, educational and employment institutions, and bridging program decision-makers need to invest in (a) ongoing data collection and research initiatives to contribute to the evidence base for the effectiveness of bridging programs; and (b) studies that develop clearer indicators of program success to support the design and development of bridging programs in a range of local contexts. Data should be drawn from current research studies, such as the Youth in Transition Survey. Research should also be carried out to understand how nonfinancial and cultural factors can affect the participation of underrepresented groups in PSE.

Institutions should employ evidence-based practices and strategies to expand, design, and deliver effective bridging programs. Research should focus on understanding the realities of students from their own perspective, thus ensuring that student voices are included in the design and delivery of bridging programs.

\section{RECOMMENDATION 7}

Knowledge mobilizers, researchers, and post-secondary institutions should develop strategies to effectively communicate the purpose and benefits of bridging programs to their institutional partners and the community at large. Communication efforts should focus on non-stigmatizing and strengths-based narratives of students requiring greater access to PSE.

The success of PSE programs requires broad support from multiple stakeholders. In order to secure this support, the broader community needs to understand the value of PSE, which requires communication strategies. Such understanding also helps ensure that participants can transition into more traditional programs and/or employment. In addition, participants need to experience their participation as opening up opportunities as a result of their strengths and potential not as a mark of their inability to meet institutional standards. In order to be successful, PSE programs need to ensure that participants do not experience them as further evidence of their failure to achieve at school. 
The complexity of factors influencing youth participation in PSE speaks to the need to better understand the realities of youth from their own perspective, and design programs that can support students in overcoming the barriers they face. 
05 // CONCLUSION

A PSE credential is an increasingly necessary commodity to remain competitive in today's labour market. ${ }^{70}$ Participation in PSE and earning a degree or diploma is linked to a person's health and career satisfaction and contributes to a healthier and more sustainable economy.

Unfortunately, the evidence is clear that certain groups of youth are underrepresented in post-secondary education (PSE) in Ontario and across Canada. ${ }^{71}$ Such groups include youth from low-income families, youth who are the first in their family to participate in PSE, Aboriginal youth, youth from rural communities, youth with dependents or a disability, and youth in or leaving government care. They face informational, motivational, and financial barriers, which affect their ability to access and persist through their PSE studies.

The complexity of factors influencing youth participation in PSE speaks to the need to (a) better understand the realities of youth from their own perspective, and (b) design programs that can support students in overcoming the barriers they face. Expanding the options for entering and persisting through PSE studies can address many of the barriers these youth face and better respond to their lived realities. ${ }^{72}$ Bridging programs present an opportunity to support underrepresented youth in their transition to PSE, providing services that can address many of their informational, motivational, and financial needs.
While all levels of government in Canada have emphasized the desirability of improved access to PSE in general, provincial and institutional responses have been inadequate in providing opportunities to reduce access barriers for underrepresented youth. Programs have largely focused on financial aid at the point of entry into PSE (access), although research has consistently showed that it is often non-financial factors, such as a lack of parental knowledge about options for accessing PSE institutions that affect PSE participation for underrepresented youth.

Bridging programs can help underrepresented students overcome barriers to PSE participation by offering alternative pathways to succeed in their programs of study, including various options for (a) attaining the credentials (usually a high school diploma) needed to enter PSE, (b) gaining academic, personal, and professional skills needed for PSE, and (c) benefitting from subject matter, admissions, personal, career, navigational, and community support.

Educational institutions, government at all levels, and employers need to collaborate to design and deliver bridging programs that best meet the needs of youth who require systemic support fulfill their PSE goals. These collaborations will ultimately contribute to the health and wellbeing of young people, their communities, and Canada as a whole.

${ }^{70}$ Canadian Council on Learning, 2011

${ }^{72}$ CSA, OSTA \& OUSA, 2011

${ }^{71}$ Weingarten et al., 2015 
Abramovitch, R. (2003). Implications of providing access in a context of inequality. In K.S. Brathwaite (Ed.), Access \& equity in the university: A collection of papers from the 30 th anniversary conference of the transitional year programme, University of Toronto (pp. 11-25). Toronto, Canada: Canadian Scholars' Press, Inc.

Benseman, J. \& Russ, L. (2003). Mapping the territory: A survey of bridging education in New Zealand. New Zealand Journal of Adult Learning, 31(1), 43-62.

Bragg, D., Harmon, T., Kirby, C., \& Kim, S. (2009). Initial results of Illinois' Shifting Gears pilot demonstration evaluation. Champaign, IL: Office of Community College Research and Leadership, University of Illinois.

Bragg, D., Oertle, K.M., Kim, S., Kirby, C., Taylor, J., Harmon, T. \& Liss, L. (2011). Illinois Adult Education Bridges: Promising practices. Transition Highlights, 4, 1-12

Brathwaite, K.S. (2003). Access and equity in the University: An introduction. In K.S. Brathwaite (Ed.), Access \& equity in the university: A collection of papers from the 30 th anniversary conference of the transitional year programme, University of Toronto (pp. 11-25). Toronto, Canada: Canadian Scholars' Press, Inc.

Burns, M., Lindoo, S., Dincau, J., Speck, R., and DeMaster, D. (2013). Implementation study of 2011 Minnesota FastTRAC Adult Career Pathways. Minnesota Department of Employment and Economic Development. Retrieved from: http://www.asa.mnscu.edu/research/docs/MN FastTRAC_ACP_Implementation_Study_Report. $\mathrm{pdf}$

Canadian Council on Learning. (2011). What is the future of learning in Canada? Retrieved from: http://eric.ed.gov/?id=ED525042

Council of Ministers of Education, Canada. (2008). Learn Canada 2020: Joint declaration Provincial and Territorial Ministers of Education. Retrieved from: http://www.cmec.ca/Publications/Lists/ Publications/Attachments/187/cmec-2020declaration.en.pdf

CSA, OSTA \& OUSA. (2011). Breaking barriers: A strategy for equal access to higher education. http://www.ousa.ca/dev/wp-content/ uploads/2011/03/Breaking-Barriers.pdf

Deller, F., \& Thomas, S. (2013). Strategies for Supporting Youth Education: A Snapshot of Early Intervention Programs in Ontario. Toronto: Higher Education Quality Council of Ontario. Retrieved from: http://www.heqco. ca/SiteCollectionDocuments/Early\%20 Interventions_ENG.pdf

Dillon, J. (2012). Black minority ethnic student navigating their way from access courses to Social Work programmes: key considerations for the selection of students. British Journal of Social Work, $41,1477-1496$
Dworsky, A., Smithgall, C. \& Courtney, M.E. (2014). Supporting youth transitioning out of foster care. Issue Brief1: Education Programs. Urban Institute OPRE Report no. 2014-66. Retrieved from: http://www.urban.org/sites/default/files/alfresco/ publication-pdfs/2000127-Supporting-YouthTransitioning-out-of-Foster-Care.pdf

Educational Policy Institute. (2009). Access, persistence, and barriers in post-secondary education: a literature review and outline of future research. Toronto: Higher Education Quality Council of Ontario

Essack, Z. \& Quayle, M. (2007). Students' perceptions of a university access (bridging) programme for social science, commerce and humanities. Perspectives in Education, 25(1), 71-84

Finnie, R., Childs, S., Qiu, T. (2012). Patterns of persistence in post-secondary education: New evidence for Ontario. Toronto: Higher Education Quality Council of Ontario.

Finnie, R., Sweetman, A. \& Usher, A. (2008). Introduction: A framework for thinking about participation in post-secondary education. In R. Finnie, R.E. Mueller, A. Sweetman, \& A, Usher. (Eds.), Who goes? Who stays? What matters? Accessing and persisting in post-secondary education in Canada (pp.3-32). Montreal \& Kingston, $O N$ : McGill-Queen's University Press.

Gordon, S. \& Nicholas, J. (2013). Students' conceptions of mathematics bridging courses. Journal of Further and Higher Education, 37(1), 109-125. Doi: $10.1080 / 0309877 X .2011 .644779$

Government of Ontario. (2015). Stepping Up: A strategic framework to help Ontario's youth succeed: Inventory of youth programs. Retrieved from: http://www.children.gov.on.ca/htdocs/ English/documents/topics/youthopportunities/ steppingup/SteppingUp-2015Inventory.pdf

Hamlin, D., Hagen Cameron, D. \& Watkins, E. (2016). Ontario's guidance counsellors: Spread thinly in an environment of growing expectations. People for Education. Toronto: March 7, 2016

Malik, S., Guan, J., Vetere, H.L., Abramovitch, R. (2011). Access, Engagement, Retention and Success of Under-represented Populations at Ryerson University: Bridges to Ryerson, the Tri-Mentoring Program and Road to Ryerson. Toronto: Higher Education Quality Council of Ontario.

Miner, R. (2011). GTA Post-Secondary Access Initiatives: Pointing the way to success. Miner and Miner Consulting. Toronto, Ontario.

Minnesota State Colleges and Universities. (2013). Enrollment, persistence, graduation and employment of Adult Basic Education learners and FastTRAC participants as Minnesota State Colleges and Universities. Retrieved from: http:// www.asa.mnscu.edu/research/docs/ABE_MN FastTRAC_Analysis_2013.pdf
Norrie K. \& Zhao, H (2011). An overview of PSE accessibility in Ontario. Toronto: Higher Education Quality Council of Ontario. Retrieved from: http:// www.heqco.ca/SiteCollectionDocuments/At-Issue8-Accessibility-ENG.pdf

Orders, S. \& Duquette, C. (2010). Enhancing access to post-secondary education in Canada: An exploration of early intervention initiatives in selected countries. Alberta: Canadian Policy Research Networks.

Perna, L. W., \& Swail, W. (2001). Pre-College Outreach and Early Intervention. Thought \& Action, 17(1), 99-110. Retrieved from http://repository.upenn.edu/ gse_pubs/287

Price, B. \& Roberts, B. (2015). Building career pathways for adult learners: An evaluation of progress in Illinois, Minnesota, and Wisconsin after eight years of Shifting Gears. Retrieved from: http://www.joycefdn.org/ assets/1/7/joyceFnd_ShiftingGears3.0.pdf

Solorzano, D., Datnow, A., Park, V. \& Watford, T. (2013). Pathways to post-secondary success: maximizing opportunities for youth in poverty. Retrieved from: http://pathways.gseis.ucla.edu/publications/ PathwaysReport.pdf

Tinto, V. \& Pusser, B. (2006). Moving from theory to action: Building a model of institutional action for student success. Retrieved from: http://web.ewu.edu/ groups/academicaffairs/IR/NPEC_5_Tinto_Pusser_ Report.pdf

The Joyce Foundation. (2013). Shifting Gears: Building new pathways for low-skilled workers to succeed in the 21st century economy. Retrieved from: http://www.joycefdn.org/assets/1/7/ ShiftingGearsEvaluationSynopsis.pdf

Weingarten et al. (2015). Canadian Post-secondary Performance: Impact 2015. Retrieved from: http:// www.hegco.ca/en-ca/Research/ResPub/Pages/ Canadian-Post-secondary-Performance-- Impact-2015.aspx

Wesley-Esquimaux, C. \& Bolduc, V. Aboriginal transition programs - literature review. Aboriginal Initiatives Office, Lakehead University. Retrieved from: https://www.lakeheadu.ca/sites/default/files/ uploads/286/22Sept14/LitReviewAug16FINAL.pdf

Wisconsin Career Pathways. (2015). Wisconsin's Regional Industry Skills Education (RISE) Career Pathway Bridges: An evaluation of career pathway bridge programming in Wisconsin 2012-2014. Retrieved from: http://risepartnership.org/Media/Default/pdf/ RISE_Career_Pathway_Bridge_Evaluation_10.2.14.pdf 
APPENDIX 1: GLOSSARY

\section{Access}

The process of enrolling in a post-secondary program.

\section{Attainment/completion}

Completing all of the requirements necessary to receive postsecondary credentials.

\section{Bridging program}

An alternative pathway for students to transition to PSE by accessing support services in gaining the necessary skills, requirements, or prerequisites to enroll in a PSE institution.

\section{Contextualized instruction}

Integrates basic reading, math, language skills, and industry/ occupation knowledge

\section{Credentials}

A certificate, degree or diploma demonstrating a qualification. For example, completing, multiple courses that receive credits toward a program can result in a degree for that program.

\section{Early intervention}

"...programs designed to provide disadvantaged students with the opportunity to develop the skills, knowledge, confidence, aspirations, and overall preparedness for college early enough in their schooling so as to influence their ultimate educational attainment levels" (Perna and Swail, 2001, p.100)

\section{Equity}

All people have fair and impartial treatment in accessing and participating in PSE and related opportunities and resources.

\section{First-generation student}

The first member of a family to attend a post-secondary institution.

\section{Participation}

All interactions youth have with post-secondary institutions, including accessing PSE, persisting through their studies, and atttaining post-secondary credentials.

\section{Pathway}

Opportunities that are available at different times in a student's life that affect their decision and ability to access PSE and navigate between employment, training, college and/or university.

\section{Persistence}

The process of participating in post-secondary education from entering a program through to graduation.

\section{Polytechnics}

PSE institutions that offer vocational or technical courses.

\section{Post-secondary education}

"...academic, technical, and vocational programs and courses taken beyond the secondary-school level" (Canadian Council on Learning, 2011, p. 17)

\section{Systemic/system-level}

Institutions that impact or respond to large groups of people or the population in general.

\section{Transition}

A period of time during which a student makes important decisions related to PSE that affects their access and persistence in PSE, such as the application process for PSE.

\section{Underrepresented}

A group identified in the research literature as being unequally represented in PSE compared to the group's representation in the general student population or compared to other groups of students. For example, Aboriginal students show rates of PSE participation that are far lower than non-Aboriginal students

(Norrie \& Zhao, 2011). 


\section{Shifting Gears Initiative - Program Evaluation Results}

\section{Wisconsin}

Wisconsin's Regional Industry Skills Education (RISE) Career

Pathway Bridge Initiative (2007) was a partnership between the Wisconsin Technical College System (WTCS) and the Wisconsin Department of Workforce Development to support career pathways and industry-driven training curricula. The program aims to allow adults who need basic skills or English language education to receive post-secondary occupational credits at the same time in order to facilitate their enrolment in and completion of occupational credits (credits related to training in a particular occupation). The evaluation of the RISE Career Pathway Bridge (2012-2014) used both participants and a control group to evaluate their program. ${ }^{73}$ The evaluation measured outcomes in: (a) post-secondary occupational enrolment, (b) credential completion among adult basic education students, and (c) subsequent effect on the student's employment and wage increases.

The total sample $(n=1,996)$ consisted of 998 bridging program participants and 998 control group participants. The control group consisted of students who were enrolled in adult basic education (ABE) courses that were associated with the RISE Career Pathway Bridge at the time they were being offered, but were not participants of the bridging programs.

In the overall sample, RISE participants enrolled in post-secondary occupational credit courses at a significantly higher rate than controls and completed more post-secondary credits. Participants were also significantly more likely to earn a PSE credential (27\% versus $11 \%$ )

English Language Learners (ELL) may particularly benefit from the RISE model. For example, $48 \%$ of the ELL bridging participants enrolled in PSE compared with $23 \%$ of the ELL control group while the $A B E$ bridging participants who completed the bridging program did not differ significantly from the ABE control group. 30\% of the ELL participants earned at least 12 post-secondary occupational credits compared with $7 \%$ of the ELL control group. $32 \%$ of the ELL participants earned a post-secondary credential compared with $14 \%$ for the ELL control group. The authors stated that some of the success of the ELL program could be attributed to the team-based teaching method (English language and Occupational teachers were paired).

\section{Minnesota}

Minnesota FastTRAC (Training, Resources, and Credentialing) Adult Career Pathways is a partnership between the state institutions of adult basic education (ABE), workforce development, human services and the Minnesota State Colleges and Universities (MnSCU) to support adults with low-wages and who are underprepared for education. ${ }^{74}$ The program follows a career pathway process to help students develop foundational knowledge and receive training toward post-secondary program completion and employment. The program model includes:

(1) contextualized instruction (combines occupation knowledge with basic reading, math and language skills),

(2) career development (addresses work culture, career exploration and planning, job placement and job retention services), and (3) support services (provides information and assistance tailored to individual needs and goals). ${ }^{75}$

An evaluation of the state's FastTRAC program based on data from the 2011-2012 academic year was carried out between 2012 and 2013 (Minnesota State Colleges and Universities, 2013). The evaluation included an analysis of data collected for students enrolled in ABE courses, FastTRAC program participants enrolled in $A B E$ and a comparison group of students not enrolled in $\mathrm{ABE}$ courses. A large majority of ABE students (82.6\%) enrolled in credits during the 2012 school year were identified as underrepresented students (eligible for the federal Pell Grant for low-income families, students of colour or first generation students) compared to a much lower number of the comparison group (53.8\%) enrolled in a credit.

There were a greater number of FastTRAC ABE participants (60\%) enrolled in a Minnesota State college or university during, or within, one year of their $A B E$ year than the $A B E$ participants who were not in the FastTRAC program (13.5\%). Among all ABE students, FastTRAC participants registered for slightly fewer credit courses but registered for double the amount of non-credit course activity than ABE students not in the FastTRAC program.

\footnotetext{
${ }^{73}$ Wisconsin Career Pathways, 2015

${ }^{74}$ Burns et al., 2013; Minnesota State Colleges and Universities, 2013
}

${ }^{75}$ Minnesota State Colleges and Universities, 2013 


\section{Illinois}

The Illinois Shifting Gears Initiative included 8 pilot sites.

Three sites used a developmental education approach and five sites used an adult education approach that included contextualized instruction, career development counselling, and transition services.

Of the 50 program participants analyzed in this study, $48 \%$ were female, $90 \%$ identified as belonging to a minority group, $17 \%$ were under 25 years of age, $84 \%$ entered the program without a high school diploma or GED, and the vast majority (90\%) had limited English language proficiency.

The authors' results are only suggestive, as there were several limitations to the study, including the small sample size and the differences between the participants of the two bridging programs, in that the developmental education program participants were more academically prepared than the adult education participants.

Nearly half of all the students completed the bridging programs, however, students enrolled in the developmental bridging programs had a higher rate of completion (72\%) compared to the adult bridging programs.

The authors suggest that the low rate of completion could be attributed to the short 15-month timeline. This timeline makes it difficult to complete the evaluation process and report on completion rates when students may take longer or have barriers to complete a bridging program in a short period of time.

The most practical findings from this study are that providing career orientation, admissions assistance, advising (student participation in career advising or coaching, academic advising or other related advising services) leads to better program outcomes.

\section{How-to Guide: Creating a Successful Bridging Program}

This comprehensive guide offers a step-by-step process to effectively develop, implement, and evaluate bridging programs. There are several examples of how to collect data for different types of bridging program evaluation, including, for example, how to collect baseline data on the students to help inform program development and monitor program progress. The guide outlines practical steps to follow for recruiting appropriate participants, engaging them, and communicating an accessible message about bridging programs. There are also several printable worksheets to help guide program developers and co-ordinators through the different stages of the process, such as developing a process map and understanding the career-planning cycle.

Access it here: http://www.iccb.org/iccb/wp-content/pdfs/ shiftinggears/ICCB_2012BridgeGuide_worksheets.pdf 


\section{Learn More:}

\section{Additional Resources}

The Council of Educators of Toronto provides comprehensive lists, descriptions, and links to access and outreach programs based on five categories:

- Transition

- Academic completion

- Outreach and engagement

- Job training, certification, pre-apprenticeship

- Demographic

Visit their programs section of the website (www.councilofeducators.ca) to view the specific programs, their descriptions, location, and contact information within each category.

\section{STUDIES EXAMINING}

\section{CANADIAN PSE ACCESS}

\section{Measuring the Effectiveness of Student Aid (MESA) project}

The Measuring the Effectiveness of Student Aid (MESA) project is a longitudinal outcome study for underrepresented students being conducted through the Canadian Education Project and the School for Policy Studies at Queen's University on behalf of the Canadian Millennium Scholarship Foundation.

\section{The Youth-in-Transition Survey (YITS)}

The YITS is a national study of Statistics Canada and Human Resources and Skills Development Canada composed of two surveys that follow youth cohorts: 1- A sample of Canadians 15 years old in December 1999 was surveyed in 2000 and every two years following; interviews with parents and officials were also conducted

2- A sample of youth aged 18-20 in December 1999 was surveyed. Information was not collected from parents. This survey is not widely studied, but it is useful for assessing persistence rates.
EARLY INTERVENTION AND POST-SECONDARY SUPPORT PROGRAMS FOR STUDENTS

\begin{tabular}{|c|c|c|}
\hline $\begin{array}{l}\text { Name and } \\
\text { Location of initiative }\end{array}$ & $\begin{array}{l}\text { Type of } \\
\text { Support }\end{array}$ & Link \\
\hline $\begin{array}{l}\text { Pathways to Education } \\
\text { Program in Ontario, } \\
\text { Quebec, Nova Scotia, } \\
\text { Manitoba and British } \\
\text { Colombia }\end{array}$ & $\begin{array}{l}\text { - Early } \\
\text { Intervention } \\
\text { - Financial } \\
\text { - Informational } \\
\text { - Academic } \\
\text { - Motivational }\end{array}$ & www.pathwaystoeducation.ca \\
\hline $\begin{array}{l}\text { Future to Discover } \\
\text { program in Manitoba }\end{array}$ & $\begin{array}{l}\text { - Early } \\
\text { Intervention }\end{array}$ & $\begin{array}{l}\text { http://www.edu.gov.mb.ca/k12/ } \\
\text { ftd/index.html }\end{array}$ \\
\hline \multirow{2}{*}{$\begin{array}{l}\text { Trimentoring Program } \\
\text { and Spanning the Gaps } \\
\text { at Ryerson University, } \\
\text { Toronto }\end{array}$} & $\begin{array}{l}\text { - Informational } \\
\text { - Motivational } \\
\text { - Academic }\end{array}$ & $\begin{array}{l}\text { http://www.ryerson.ca/ } \\
\text { studentlife/trimentoring//index. } \\
\text { html }\end{array}$ \\
\hline & - Transitional & $\begin{array}{l}\text { http://ce-online.ryerson.ca/ce/ } \\
\text { default.aspx?id=3257 }\end{array}$ \\
\hline $\begin{array}{l}\text { Ontario Association of } \\
\text { Children's Aid Society } \\
\text { (OACAS) YouthCan: } \\
\text { Aftercare Benefits } \\
\text { Initiative, Youth In } \\
\text { Transition education } \\
\text { resources, and Crown } \\
\text { Ward Education } \\
\text { Championship Teams }\end{array}$ & $\begin{array}{l}\text { - Financial } \\
\text { - Informational } \\
\text { - Academic }\end{array}$ & $\begin{array}{l}\text { http://www.oacas.org/what-we- } \\
\text { do/child-welfare-operations- } \\
\text { excellence/aftercare-benefits- } \\
\text { initiative/ } \\
\text { http://ontarioyouthcan.org/rsyt. } \\
\text { youth/?page_id=20 } \\
\text { http://crownwardeducation.co }\end{array}$ \\
\hline Ontario Access Grant & - Financial & $\begin{array}{l}\text { https://osap.gov.on.ca/ } \\
\text { OSAPPortal/en/A-ZListofAid/ } \\
\text { PRDR008163.html }\end{array}$ \\
\hline $\begin{array}{l}\text { Ontario Access Grant } \\
\text { for Crown Wards } \\
\text { (OAG-CW) }\end{array}$ & - Financial & $\begin{array}{l}\text { https://osap.gov.on.ca/ } \\
\text { OSAPPortal/index.htm }\end{array}$ \\
\hline $\begin{array}{l}\text { CanLearn of the } \\
\text { Government of Canada }\end{array}$ & $\begin{array}{l}\text { - Financial } \\
\text { - Informational }\end{array}$ & $\begin{array}{l}\text { http://www.canlearn.ca/eng/ } \\
\text { index.shtml }\end{array}$ \\
\hline $\begin{array}{l}\text { Student Financial } \\
\text { Assistance of the } \\
\text { Government of Canada }\end{array}$ & - Financial & $\begin{array}{l}\text { http://www.esdc.gc.ca/en/ } \\
\text { student_financial_aid/index.page }\end{array}$ \\
\hline
\end{tabular}




\section{Creating Multiple Pathways to Success}

Young people need multiple and flexible pathways to achieve credentials, employment and economic success-combining work experience, education, training and supports.

\section{WORK EXPERIENCE}

Work experience can help youth build skills and can open up valuable opportunities as youth prepare for work and a career.

\section{COMMUNITY SUPPORTS}

Community supports are needed to help youth get back on track; stay on track; and get help navigating school, work and community.
Youth who drop out of high school can pursue alternative education and career opportunities.

\section{RE-ENGAGEMENT CENTERS}

BACK-ON-TRACK OPTIONS

EARN/LEARN PROGRAMS

With college prep or bridge programs, youth can better prepare to be successful.

\begin{tabular}{|l|}
\hline COLLEGE BRIDGE COURSES \\
\hline FINANCIAL ADVISING \\
\hline GUIDANCE COUNSELING \\
\hline
\end{tabular}

\section{.}

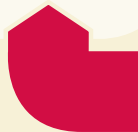

LEAVE

POSTSECONDARY
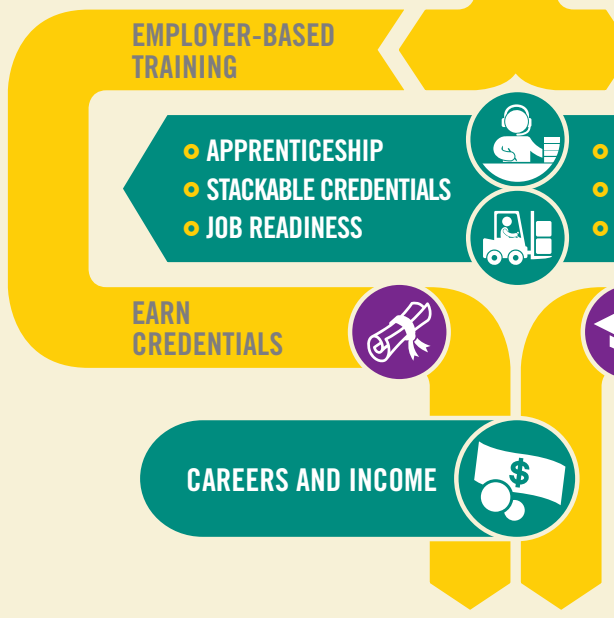

\section{ENTER HIGH SCHOOL}

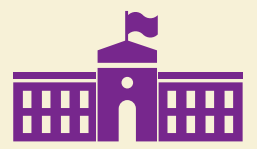

HIGH SCHOOL

LEAVE
HIGH SCHOOL

- CUSTOMIZED TRAINING

- PART-TIME JOB

- CONSERVATION CORPS

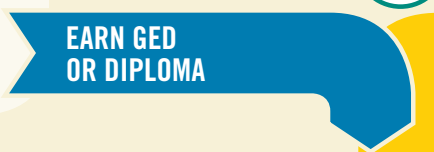

NOT READY

FOR COLLEGE

\section{COLLEGE READY}

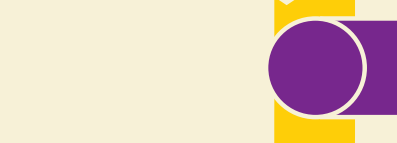

ENTER POSTSECONDARY

EXPERIENCE

- COMMUNITY SERVICE

- INTERNSHIP

GRADUATE

HIGH SCHOOL
ACADEMIC TUTORING

LEADERSHIP DEVELOPMENT

MENTORING AND NAVIGATION

COLLEGE PREP/DUAL ENROLLMENT
FINANCIAL AND HOUSING AID

CAREER NAVIGATION

SOCIAL NETWORKS

SUPPORT OF FAMILY

Source: Annie E Casey Foundation. (2016). Youth and Work: restoring teen and young adult connection to opportunity. 


\section{MOVING THE DIAL ON}

YOUTH WELLBEING:

ABOUTTHIS SERIES

Moving the Dial on Youth Wellbeing is a series of reports on topics relevant to improving youth outcomes in Ontario. We selectively review, synthesize and translate practice-relevant research, evaluation and experiential evidence from refereed and grey literature in order to provide the youth sector stakeholders with a contextual understanding and key strategies that can be used to enhance youth wellbeing and realize the vision set forward in Ontario's Stepping Up Youth Outcomes Framework.

\section{1) Who are the reports for?}

Moving the Dial reports are written for youth sector stakeholders. However, we recognize that the "youth sector" is multi-faceted. Practices across the youth sector are diverse and include people working in a broad range of settings. Report authors work to identify ways in which different youth sector stakeholders can "move the dial" for youth wellbeing based on their position.

\section{2) How do these reports engage with evidence?}

We understand evidence as multidimensional. While scientific evidence is one form of knowledge, we also recognize that practitioner and lived experience constitutes other forms of knowledge. Moving knowledge into practice is a dynamic process that requires ongoing engagement with knowledge across multiple locations.

\section{3) How should I use the reports to "move the dial" for improved youth} wellbeing outcomes?

Our reports are the result of a selective, but non-systematic, review of literature and evidence that is available at the time of writing. Evidence changes and evolves. It is therefore important to assess knowledge claims with this dynamism in mind. While the reports describe research and youth work "best practices" or models, these descriptions are not intended to be endorsements. YouthREX does not advocate for particular positions or views expressed in the reports. The responsibility for the information and the opinions contained in these reports lie entirely with the author(s). 



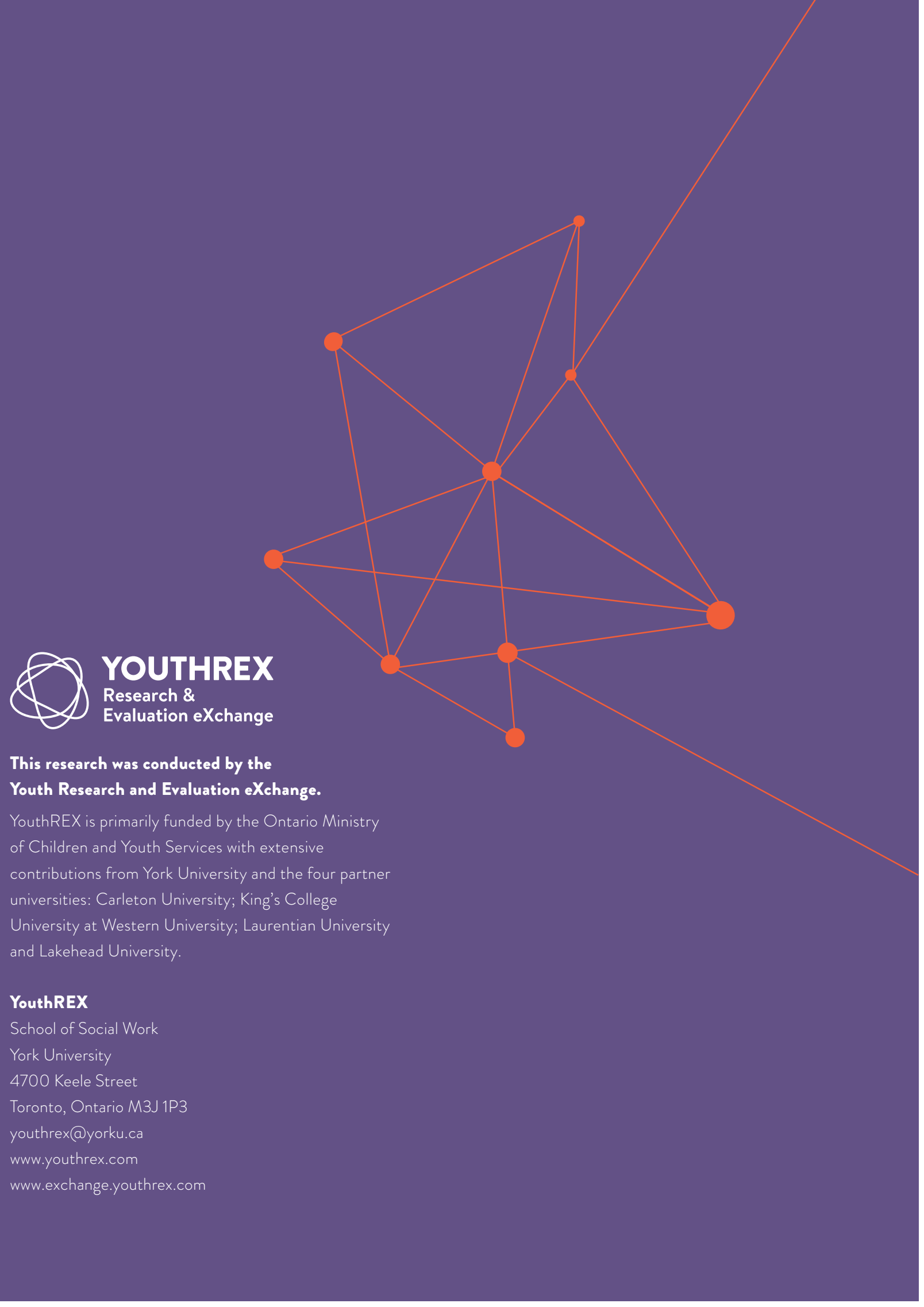

